\title{
Polarization-Sensitive Second Harmonic Imaging of Collagen Fibers in Biological Tissue
}

B-M. Kim, P. C. Stoller, K. M. Reiser, A. M. Rubenchik, L. B. Da Silva

U.S. Department of Energy

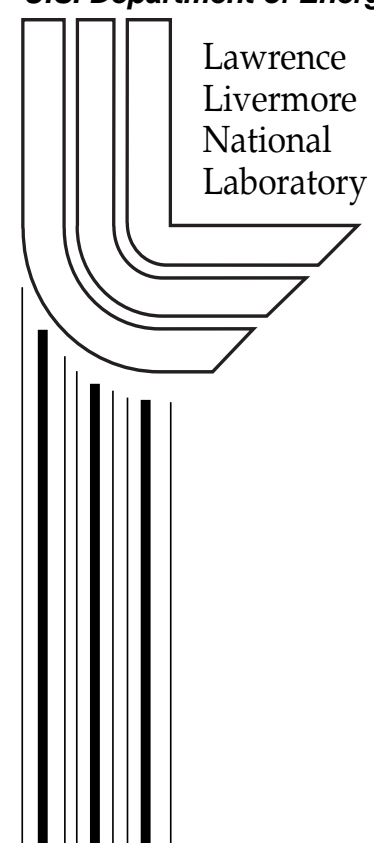

This article was submitted to 4th Pacific Rim Conference on Lasers and Electro-Optics, Chiba, Japan, July 15-19, 2001

February 1, 2001 


\section{DISCLAIMER}

This document was prepared as an account of work sponsored by an agency of the United States Government. Neither the United States Government nor the University of California nor any of their employees, makes any warranty, express or implied, or assumes any legal liability or responsibility for the accuracy, completeness, or usefulness of any information, apparatus, product, or process disclosed, or represents that its use would not infringe privately owned rights. Reference herein to any specific commercial product, process, or service by trade name, trademark, manufacturer, or otherwise, does not necessarily constitute or imply its endorsement, recommendation, or favoring by the United States Government or the University of California. The views and opinions of authors expressed herein do not necessarily state or reflect those of the United States Government or the University of California, and shall not be used for advertising or product endorsement purposes.

This is a preprint of a paper intended for publication in a journal or proceedings. Since changes may be made before publication, this preprint is made available with the understanding that it will not be cited or reproduced without the permission of the author.

This work was performed under the auspices of the United States Department of Energy by the University of California, Lawrence Livermore National Laboratory under contract No. W-7405-Eng-48.

This report has been reproduced directly from the best available copy.

Available electronically at http://www.doc.gov/bridge

Available for a processing fee to U.S. Department of Energy

And its contractors in paper from

U.S. Department of Energy

Office of Scientific and Technical Information

P.O. Box 62

Oak Ridge, TN 37831-0062

Telephone: (865) 576-8401

Facsimile: (865) 576-5728

E-mail: reports@adonis.osti.gov

Available for the sale to the public from

U.S. Department of Commerce

National Technical Information Service

5285 Port Royal Road

Springfield, VA 22161

Telephone: (800) 553-6847

Facsimile: (703) 605-6900

E-mail: orders@ntis.fedworld.gov

Online ordering: http://www.ntis.gov/ordering.htm

OR

Lawrence Livermore National Laboratory

Technical Information Department's Digital Library

http://www.llnl.gov/tid/Library.html 


\title{
Polarization-sensitive second harmonic imaging of collagen fibers in biological tissue
}

\author{
Beop-Min Kim, Patrick C. Stoller, Karen M. Reiser, Alexander M. Rubenchik, Luiz B. Da Silva \\ Medical Technology Program, Lawrence Livermore National Laboratory \\ 7000 East Ave. L-174, Livermore, CA 94550, USA \\ Phone : 925-423-3262 \\ FAX : $925-424-2778$ \\ E-mail : kim12@llnl.gov
}

\begin{abstract}
The second order nonlinear optical properties and orientation of collagen fibers were measured simultaneously using polarization modulation and phase sensitive detection.

\section{Introduction}

Collagen is a structural protein found throughout animal and human tissues. It plays a key role in the structure and function of virtually every organ system. Collagen, which has a very long half-life, undergoes progressive modification over months to years after original synthesis due to both natural and pathological causes. Pathological change in collagen is induced by cancer (loss of basement membrane integrity and disruption of extracellular matrix), nonenzymatic glycation (diabetes), abnormal wound healing, and vascular disease. In many cases, rapid and noninvasive diagnostic tools to detect these changes are highly desirable. Often, time-consuming biopsy is the only choice in the clinic.

Recently, second harmonic generation (SHG) has been used to image cell membranes ${ }^{1-2}$ and other macromolecules such as collagen ${ }^{3-6}$. Collagen possesses non-zero second order nonlinear susceptibility due to its micro-and macro-structure which is a necessary condition for SHG. Thanks to recent advances in femtosecond laser technology, it has become possible to image collagen without damaging it. In this article, we present recent results that show that SHG from collagen is dependent on light polarization and that relatively rapid characterization of collagen can be performed using a polarization modulation technique that employs an electro-optic modulator. Also, we present a mathematical model that describes the polarization dependence of SHG in collagen.
\end{abstract}

\section{Materials and Methods}

Current study was done using rat-tail tendon, for the following reasons: (1) it contains only one type of collagen (type I); (2) it is highly organized on both the molecular and macroscopic level; (3) rat-tail tendons have been extensively studied and there are many data available on their biochemical and biomechanical properties. Therefore, this study will lead to an improved understanding of the relationship between SHG and these properties.
We used a Ti:Sapphire oscillator (Tsunami, Spectra-Physics) to generate $5 \mathrm{~nJ}, 100 \mathrm{fs}$ pulses at a wavelength of $800 \mathrm{~nm}$ and with a repetition rate of $82 \mathrm{MHz}$. The femtosecond beam was reflected off of a dichroic mirror and focused down to a rat-tail tendon sample using a $\mathrm{NA}=0.42$ microscope objective. The generated second harmonic light was collected using the same objective, transmitted by the dichroic mirror, and collected by the photomultiplier tube.

\section{Results and Discussion}

For the cylindrical symmetry of bundles of parallel collagen fibrils, the second order nonlinear polarizability becomes,

$$
\vec{P}=a \vec{s}\left(\vec{s} \cdot \vec{E}_{l}\right)^{2}+b \vec{s}\left(\vec{E}_{l} \cdot \vec{E}_{l}\right)+c \vec{E}_{I}\left(\vec{s} \cdot \vec{E}_{I}\right)
$$

where $\vec{s}$ is a unit vector in the direction of the fibrils, $\vec{E}_{1}$ is the electric field of the incoming laser beam, and $a, b$, and $c$ are constants. Making the paraxial approximation and assuming Kleinman symmetry, the second harmonic signal is given $b^{7}$,

$$
\begin{aligned}
I_{S H G} & =\frac{1}{8}\left(3+20 \gamma+40 \gamma^{2}\right)+\frac{1}{2}\left(I+6 \gamma+8 \gamma^{2}\right) \cos (2 \alpha) \\
& +\frac{1}{8}(I+4 \gamma) \cos (4 \alpha) \\
& =C_{0}+C_{1} \cos (2 \alpha)+C_{3} \cos (4 \alpha)
\end{aligned}
$$

where $\gamma$ is a parameter that is defined by the coefficients of the second order nonlinear susceptibility tensor $\chi^{(2)}$ and $\alpha$ is the angle between the linear polarization of the excitation pulse and the normal to the collagen fibers.

Equation (2) implies that SHG is dependent on the polarization angle. The image in Fig. 1 was obtained by continuously rotating the half-wave plate and thus rotating the beam polarization at different depths ( $z$ ) in the rat-tail tendon. The model was fit to these data and the fit produced values of $\gamma=-0.7$ -1.0 throughout the depth.

Since rotating the half wave plate is tedious and time-consuming, we implemented a fast polarization modulation scheme by inserting an electro-optic modulator (EOM) and quarter wave plate into the 


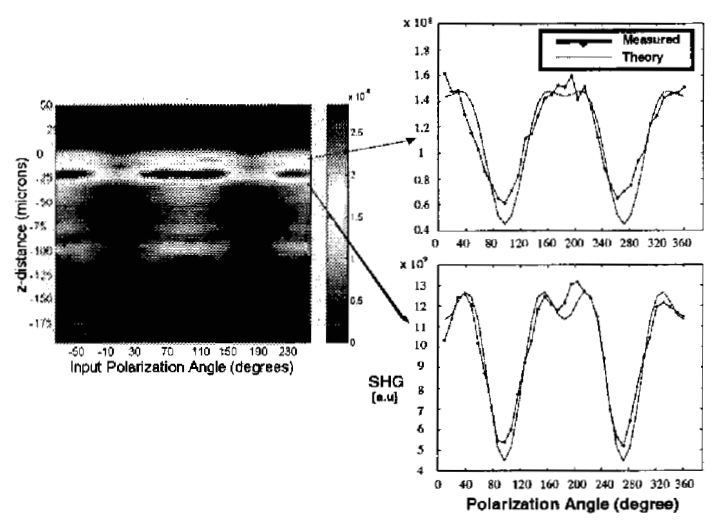

Fig. 1. One dimensional image of the rat-tail tendon with varying polarization angle of the excitation pulse. It shows reasonable fit with the model presented ( $\gamma$ is approximately -0.75 ).

beam path. A $3 \mathrm{kHz}$ sawtooth voltage signal was applied to the EOM, thus continuously sweeping the polarization angle from $-90^{\circ}$ to $+90^{\circ}$.

In Equation (2), the coefficients $C_{1}$ and $C_{2}$ of the first and second modulation harmonic, respectively, can be measured separately by using a lock-in amplifier and providing the sawtooth modulating signal as the reference. By taking the ratio between $\mathrm{C}_{1}$ and $\mathrm{C}_{2}$, the nonlinear susceptibility parameter, $\gamma$, can be calculated. Fig. 2. shows the measured ratio between $C_{2}$ and $C_{1}$ and also the ratio between $C_{3}$ (the coefficient of the third modulation harmonic) and $C_{1}$ which is supposed to be zero according to our model. From this figure, it is clear that the parameter $\gamma$ does not change significantly with depth.

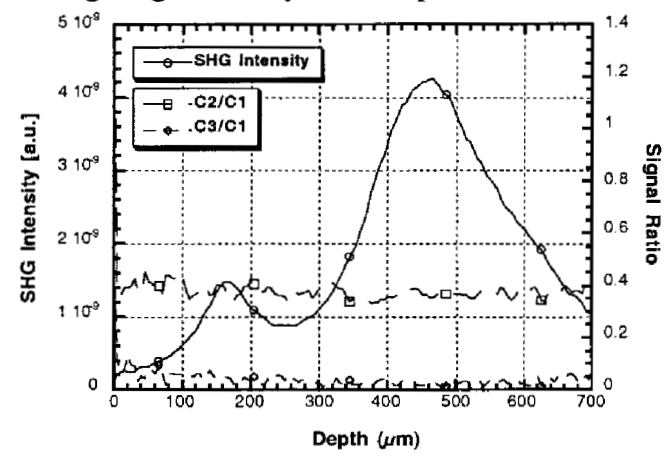

Fig. 2. SHG intensity and the ratio between $C_{1}, C_{2}$, and $C_{3}$.

Equation (2) also shows that the orientation of the collagen fibers can be estimated by measuring the phase shift of the lock-in signal relative to the sawtooth reference signal. The relative orientation of a collagen fascicle is given by half of the lock-in amplifier's phase measurement. We tested this by imaging two rat-tail tendon fascicles oriented perpendicular to each other and mounted between two glass slides. We scanned along one of the tendons. As predicted by the model, the $90^{\circ}$ difference in collagen orientation angles shows up as a $180^{\circ}$ phase shift.

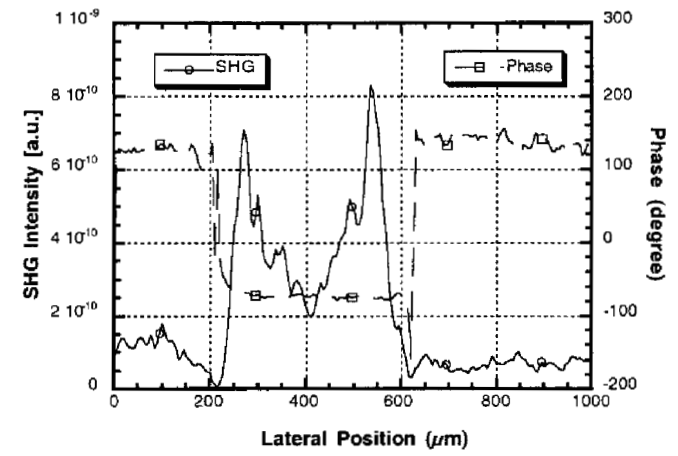

Fig. 3. Lock-in measurement of phase shift for superimposed rattail tendons at right angle.

In conclusion, a parameter related to the second order nonlinear susceptibility and the collagen fiber orientation can be measured simultaneously by using polarization modulation and phase sensitive detection. This technique may have application in the characterization of different collagen types or in studying various pathologies that alter collagen structure, such as skin cancer, non-enzymatic glycation (diabetes), abnormal wound healing, or vascular disease.

\section{References}

1. P. J. Campagnola, M. Wei, A. Lewis, and L. M. Loew, Biophysical Journal, vol. 77, pp. 33413349, 1999

2. G. Peleg, A. Lewis, M. Linial, and L. M. Loew, Proc. Natl. Acad. Sci., vol. 96, pp. 6700-6704, 1999

3. S. Roth and I. Freund, Journal of Chemical Physics, vol. 70, pp. 1637-1643, 1979

4. B.-M. Kim, J. Eichler, K. M. Reiser, A. M. Rubenchik and L. B. Da Silva, Lasers in Surgery and Medicine, vol. 27, pp. 329-335, 2000

5. B.-M. Kim, J. Eichler, and L. B. Da Silva, Applied Optics, vol. 38, no. 34, pp. 7145-7150, 1999

6. Y. Guo, P. P. Ho, H. Savage, D. Harris, P. Sacks, S. Schantz, F. Liu, N. Zhadin, and R. R. Alfano, "Second-harmonic tomography of tissue," Optics Letters 22, 1323-1325 (1997).

7. P. C. Stoller, B.-M. Kim, A. M. Rubenchik, K. M. Reiser, and L. B. Da Silva, Journal of Biomedical Optics (submitted)

** This work was performed under the auspices of the U.S. Department of Energy at Lawrence Livermore National Laboratory under contract $W$ $7405-E N G-48$ 